\title{
Pluripotency factor binding and Tsix expression act synergistically to repress Xist in undifferentiated embryonic stem cells
}

\author{
Tatyana B Nesterova ${ }^{1 \dagger}$, Claire E Senner ${ }^{1,2 \dagger}$, Janina Schneider ${ }^{1,3}$, Tilly Alcayna-Stevens ${ }^{1}$, Anna Tattermusch', \\ Myriam Hemberger ${ }^{2}$ and Neil Brockdorff ${ }^{*}$
}

\begin{abstract}
Background: Expression of Xist, the master regulator of $X$ chromosome inactivation, is extinguished in pluripotent cells, a process that has been linked to programmed $X$ chromosome reactivation. The key pluripotency transcription factors Nanog, Oct4 and Sox2 are implicated in Xist gene extinction, at least in part through binding to an element located in Xist intron 1. Other pathways, notably repression by the antisense RNA Tsix, may also be involved.

Results: Here we employ a transgene strategy to test the role of the intron 1 element and Tsix in repressing Xist in ES cells. We find that deletion of the intron 1 element causes a small increase in Xist expression and that simultaneous deletion of the antisense regulator Tsix enhances this effect.

Conclusion: We conclude that Tsix and pluripotency factors act synergistically to repress Xist in undifferentiated embryonic stem cells. Double mutants do not exhibit maximal levels of Xist expression, indicating that other pathways also play a role.
\end{abstract}

\section{Background}

In female mammals a developmentally regulated process, $\mathrm{X}$ inactivation, ensures silencing of a single $\mathrm{X}$ chromosome, balancing levels of $\mathrm{X}$-linked genes relative to males [1]. X inactivation is mediated by the cis-acting non-coding RNA Xist that is transcribed from and coats the inactive $\mathrm{X}$ chromosome (Xi) elect [2]. Coating by Xist RNA triggers epigenetic modifications that silence transcription and establish a heritable heterochromatic state [3].

$\mathrm{X}$ inactivation in the mouse occurs in two waves; imprinted $\mathrm{X}$ inactivation of the paternal $\mathrm{X}$ chromosome (Xp) that is initiated in two to four cell embryos and maintained in all cells until the blastocyst stage, and random $\mathrm{X}$ inactivation, initiated in the postimplantation epiblast. Embryo precursors in the inner cell mass (ICM) of the blastocyst reactivate $\mathrm{Xp}$, reversing imprinted $\mathrm{X}$ inactivation and setting the ground state for the onset of random X inactivation $[4,5]$. XX embryonic stem (ES) cells,

\footnotetext{
* Correspondence: neil.brockdorff@bioch.ox.ac.uk

+ Contributed equally

'Developmental Epigenetics Group, Department of Biochemistry, University of Oxford, South Parks Road, Oxford, OX1 3QU, UK

Full list of author information is available at the end of the article
}

which are derived from the ICM, mirror this ground state, retaining two active $\mathrm{X}$ chromosomes [6,7]. In contrast extraembryonic trophectoderm and primitive endoderm lineages and cell lines derived thereof retain the imprinted $\mathrm{X}$ inactivation pattern through embryogenesis [8-11].

$\mathrm{X}$ chromosome reactivation also occurs in XX primordial germ cells during migration towards the genital ridges [12-14], and similarly during experimental reprogramming of XX somatic cells, either by cloning, cell fusion with pluripotent cells or induced pluripotent stem cell technology [15-17]. In all of these examples, including ICM cells, $\mathrm{X}$ reactivation is linked to extinction of Xist RNA expression from Xi. Xist-dependent reversibility of $\mathrm{X}$ inactivation is specific to pluripotent lineages and/or cell types as conditional knockout of $X i s t$ in somatic cells does not lead to $\mathrm{X}$ reactivation $[18,19]$.

The mechanism underlying extinction of Xist expression in pluripotent cells is poorly understood. The antisense repressor Tsix is a candidate but deletion of the Tsix promoter in undifferentiated ES cells leads to only low levels of Xist upregulation and in a small proportion

\section{Ciomed Central}


of cells [20,21]. Moreover Tsix expression is not observed in primordial germ cells (PGCs) at the time of $\mathrm{X}$ reactivation [13]. A second candidate is a Nanog/Oct4/Sox 2 (NOS)-binding element located in Xist intron 1 [22]. Depletion of Nanog or Oct4 does indeed increase levels of Xist RNA. Set against this, a recent study found that deletion of the intron 1 NOS does not increase Xist RNA levels in undifferentiated XX ES cells, although there was an effect on $\mathrm{X}$ chromosome choice following differentiation in vitro [23]. In this study we have used a transgenic strategy to analyse the role of the intron 1 NOS and Tsix in repressing Xist in ES cells. We show that deletion of the intron 1 element moderately increases Xist expression in ES cells and that this effect is amplified by simultaneous deletion of Tsix. We conclude that Tsix and the intron 1 NOS function synergistically to repress Xist in undifferentiated ES cells.

\section{Results and Discussion}

Repositioning and inversion of the intron 1 NOS does not affect Xist regulation

A previous study demonstrated that acute downregulation of Oct4 in XY ES cells leads to rapid depletion of Oct4, Nanog and Sox 2 proteins at the binding region of Xist intron 1 and considerable upregulation of Xist expression [22]. This effect, however, is observed only in $10 \%$ of cells and is accompanied by cell differentiation. To exclude the possibility of an indirect effect of Oct4/ Nanog depletion on Xist regulation, we decided to directly test the role of NOS binding sites within Xist intron 1. For initial analysis we took advantage of a previously generated XY ES cell line (NBXT INV1) carrying a targeted inversion between exon 1 and intron 4 of the Xist locus [24]. In this cell line, the intron 1 element is retained but in a different position and in a reversed orientation (Figure 1A). We first analysed by RNA fluorescent in situ hybridisation (FISH) if Xist remained repressed in these cells. We found the culture to be indistinguishable from its parental wild-type counterpart (129/ 1 ), with one punctate signal in each cell (Figure 1B). As Xist remained repressed in these cells we then carried out chromatin immunoprecipitation (ChIP) to determine if $X i s t$ repression was maintained in the presence or absence of Nanog binding to intron 1 (Figure 1C). Again we found NBXT INV1 and 129/1 to be indistinguishable, with Nanog binding occurring at the Oct4 proximal promoter and Xist intron 1 to the same extent in both cell lines. As expected, Nanog binding was not detected in the extraembryonic endoderm (XEN) cell line where Nanog is not expressed ([8] and our unpublished data). Thus, it appears that reversing the orientation of the binding site in Xist intron 1 does not interfere with either Nanog binding or regulation of Xist expression.

\section{Deletion of Xist intron 1 within a P1 construct triggers Xist upregulation}

Since inversion of Xist intron 1 did not disrupt its purported function we decided to delete the region by Galactokinase (GalK)-mediated recombineering [25] in a P1-derived artificial chromosome carrying the entire Xist genomic sequence plus $34.2 \mathrm{~kb}$ upstream of the Xist transcriptional start site (TSS) and $24 \mathrm{~kb}$ downstream of Xist exon 8, and therefore encompassing most of the known critical Xist cis regulatory elements. As a positive control we analysed ES cells transfected with the P1 construct with an inducible promoter (tetracycline responsive element; TRE) introduced at the Xist TSS. Addition of doxycycline caused a robust Xist transcription and accompanying chromosomal acquisition of histone modifications associated with the silenced state (Additional file 1).

A bioinformatic search for NOS consensus sequences within the Xist locus revealed three potential Nanog-binding sites and one Oct4/Sox2-binding site located in close proximity to each other within intron 1 (data not shown). The identified sites lay within the region that showed the highest enrichment for Nanog and Oct4 proteins ([22] and our unpublished data). Based on this data we designed a strategy to remove the minimal region encompassing these sites in the P1 clone. The homology arms for recombineering were designed to delete $0.3 \mathrm{~kb}$ of the intron 1 region without introducing any foreign sequences (Figure 2A; see Methods). The resulting construct $\Delta$ int 0.3 as well as the parental P1 clone (wild type; wt) were co-lipofected with a selection plasmid carrying puromycin resistance under the control of mammalian Phosphoglycerate kinase promoter (pPGKpuro) into the 129/1 XY ES cell line and puromycin-resistant colonies were picked and analysed by PCR for the presence of a P1 construct. Twelve P1-positive clones for each construct were selected randomly for analysis of Xist expression.

RNA FISH analysis of Xist and Tsix transcripts showed an upregulated Xist domain is present in a proportion of cells in the majority of the clones carrying $\Delta$ int0.3 (Figure $3 \mathrm{~A}$ ). The proportion of Xist domains varied considerably between different clones $(0 \%$ to $69 \%$ ) and the size and appearance of the domains varied between clones as well as between cells of the same clone (Figure 2A, 3A). Generally, domains were smaller than those observed in female somatic cells, but in some cells they were diffuse and occupied a large area of the nucleus. In contrast, all but one clone with the control wt P1 construct showed one or two punctate signals, corresponding to the endogenous and transgenic Xist (Figure 2B, 3A). The single exception, clone D6, showed a domain reminiscent of Xist in female somatic cells. However, an equivalent signal was detected with both 
A

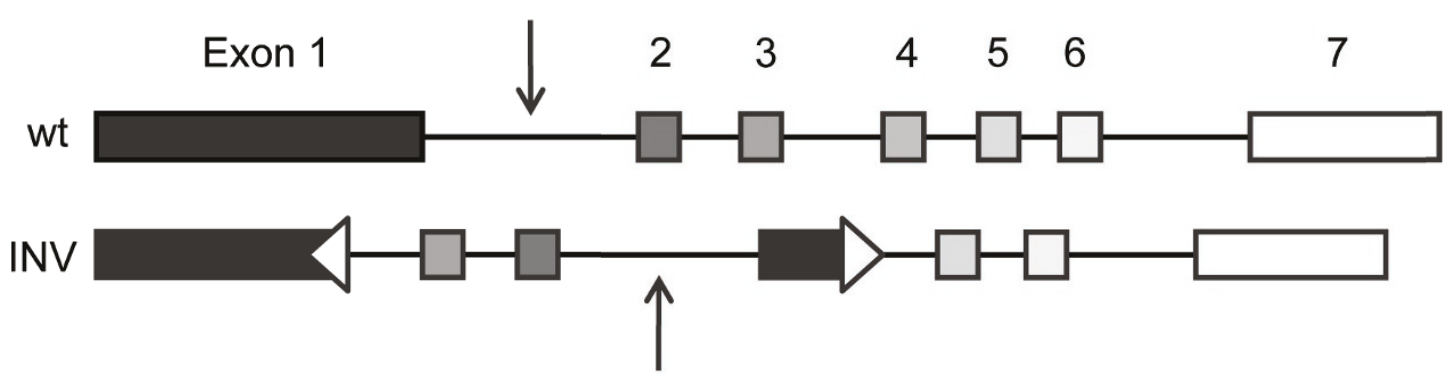

B
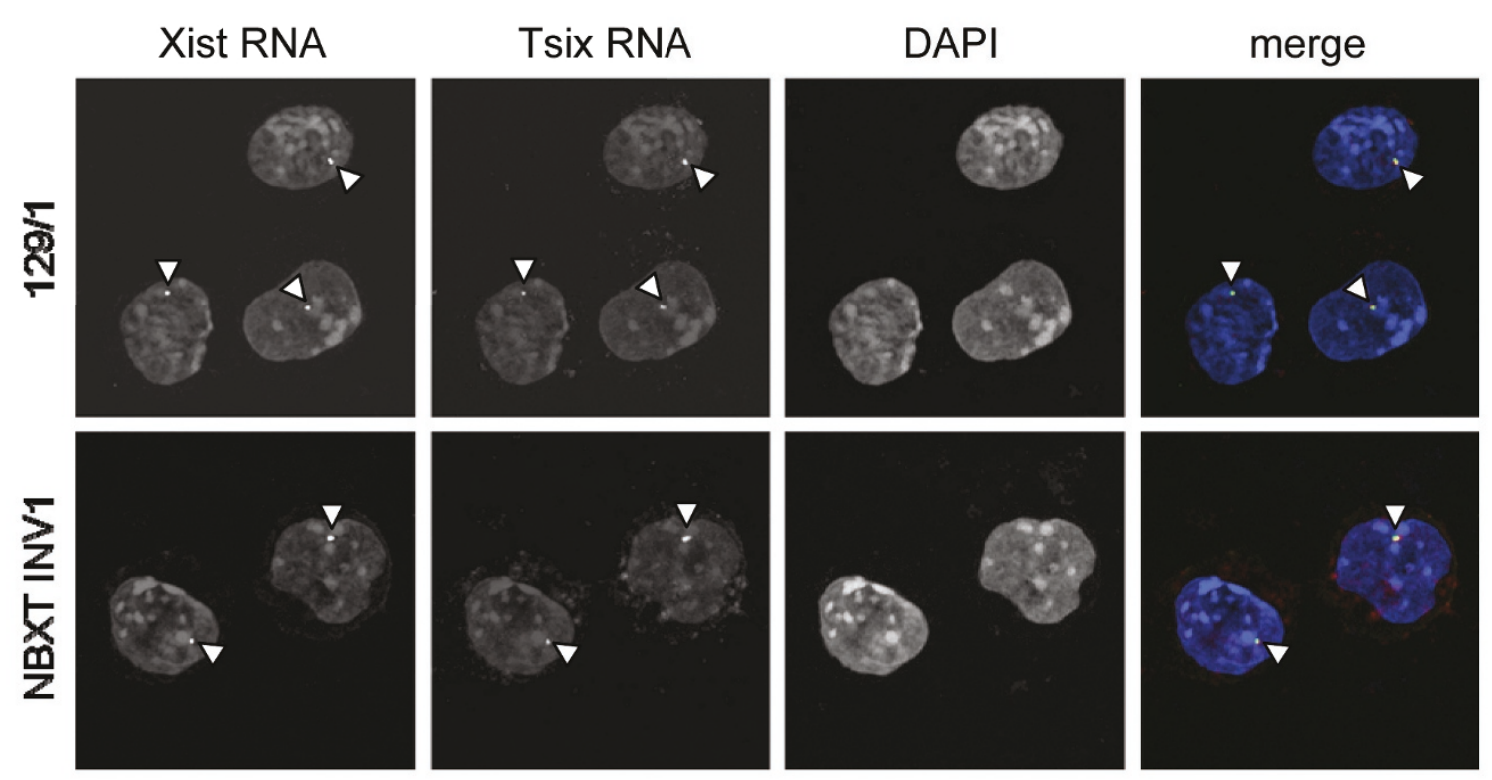

C

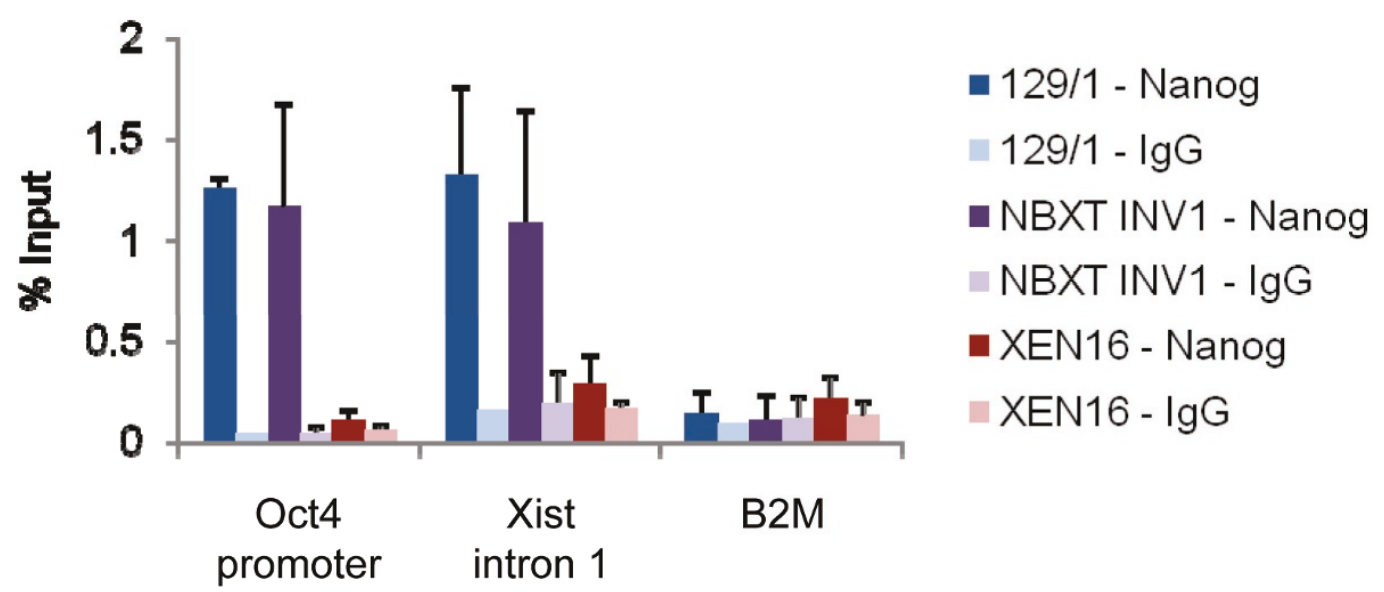

Figure 1 Analysis of Nanog binding to Xist Intron 1 in ES cells carrying a targeted inversion in Xist. (A) Schematic representation of the wt and INV Xist alleles. Arrows indicate the position of the NOS binding site. (B) RNA FISH images showing Xist (green) and Tsix (red) expression in wt ES cells (129/1) and those carrying a targeted inversion in the Xist locus (NBXT INV1). Arrowheads point to punctate signal. DNA was counterstained with DAPI (blue). (C) Occupancy of the Oct4 promoter and Xist intron 1 by Nanog in wt ES cells (129/1) and NBXT INV1. XEN cells which do not express Nanog were used as a negative control. The promoter of the housekeeping gene B2M was used as a negative control for Nanog binding. DAPI: 4',6-diamidino-2-phenylindole; ES: embryonic stem; FISH: fluorescent in situ hybridisation; NBXT INV1: Xist allele carrying a targeted inversion; wt: wild type; XEN: extraembryonic endoderm. 
A
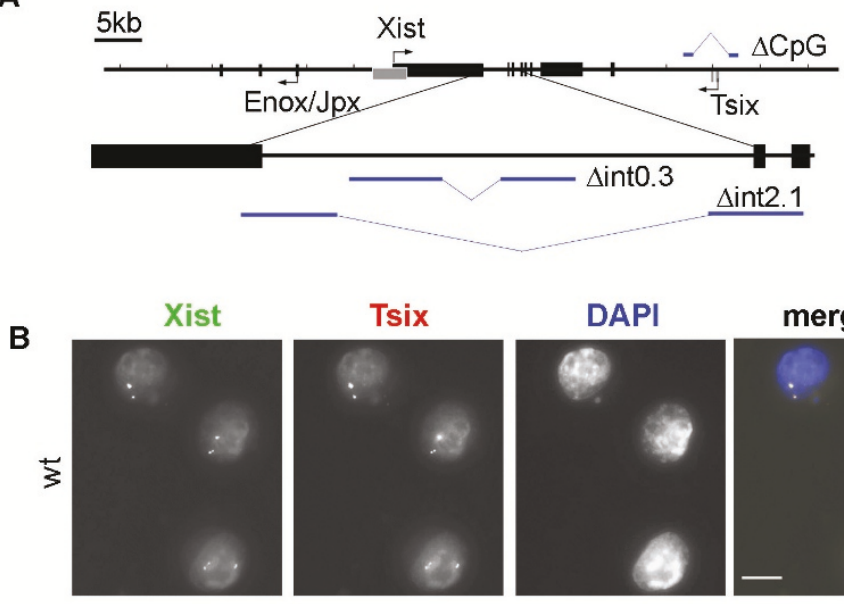

merge
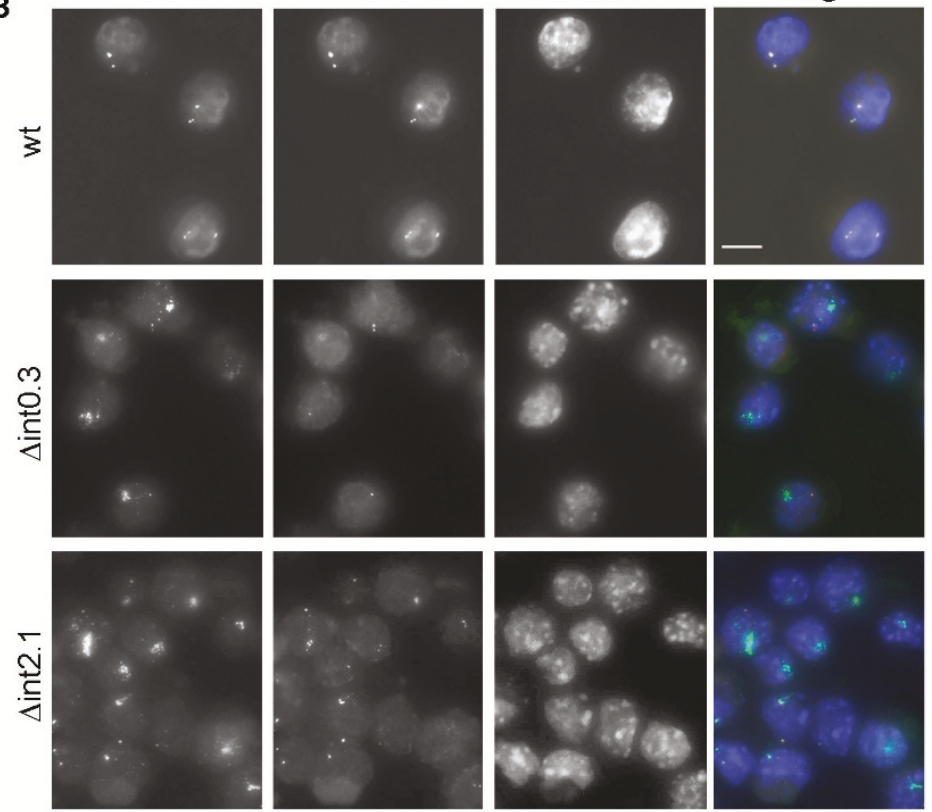

C

D
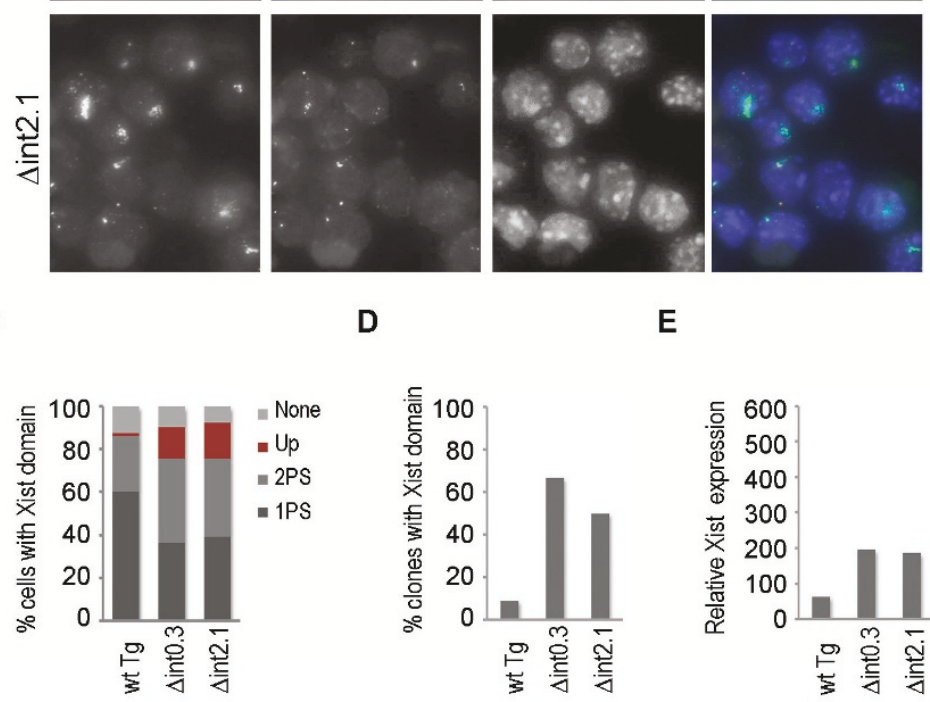

E

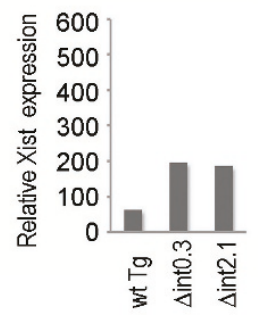

Figure 2 Deletion of NOS binding region within Xist intron 1 causes moderate upregulation of transgenic Xist expression in undifferentiated XY ES cell lines. (A) schematic representation of X inactivation centre region cloned into bacteriophage clone P1. Xist and Tsix exons are indicated as black and grey rectangles, respectively. The first three exons of Enox/Jpx are also shown. The direction of transcription for each locus is indicated by arrows. An enlarged region spanning Xist exons 1 to 3 is shown underneath the main schematic. Blue horizontal

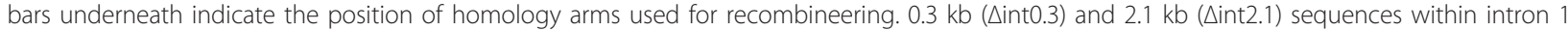
deleted from P1 clone by recombineering both encompass NOS-binding region. Blue lines above the main schematic indicate the position of the homology arms and the deleted region of the Tsix promoter $(\triangle \mathrm{CPG})$. (B) RNA FISH analysis of Xist and Tsix expression in undifferentiated XY

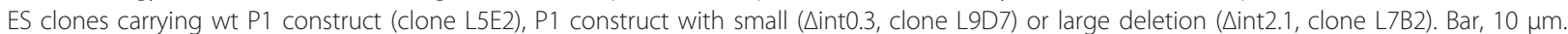
(C) A graph showing proportional representation of four patterns of Xist expression in XY ES clones carrying P1 transgenes: light grey, no detectable Xist expression; red, upregulated Xist cloud; grey, two punctate Xist signals; dark grey, one punctate Xist signal. Average data for 12 clones of each genotype are shown. Individual clone data are shown in Figure 3A. (D) Graph showing a percentage of clones with upregulated Xist. (E) qRT-PCR analysis of Xist expression in XY ES clones carrying either wt P1 or P1 with $0.3 \mathrm{~kb}(\Delta$ int0.3) or $2.1 \mathrm{~kb}(\Delta$ int2.1) deletions in Xist intron 1. All data is normalised to $\beta$-actin transcript levels and presented relative to the wt XY ES (129/1) Xist RNA level. Average data for 12 clones of each genotype are shown. Individual clone data are shown in Figure 3B. ES: embryonic stem; FISH: fluorescent in situ hybridisation; NOS: Nanog/Oct4/Sox2; qRT-PCR: quantitative reverse transcription polymerase chain reaction; wt: wild type. 
A

\section{P1Xist wt}

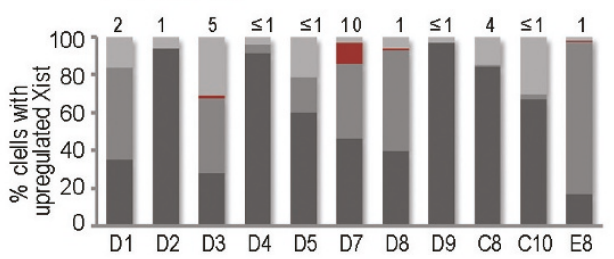

P1Xist $\triangle$ CpG

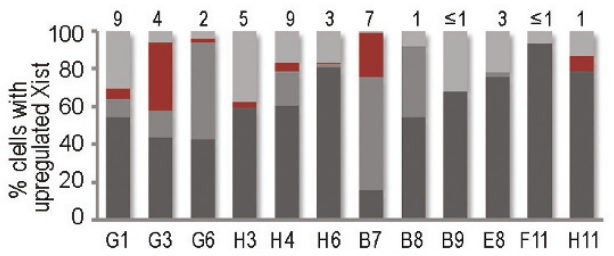

P1Xist $\Delta$ int0.3

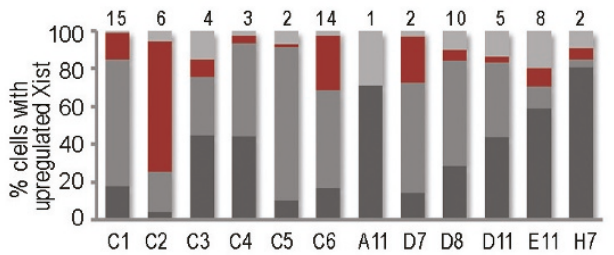

P1Xist Lint2.1

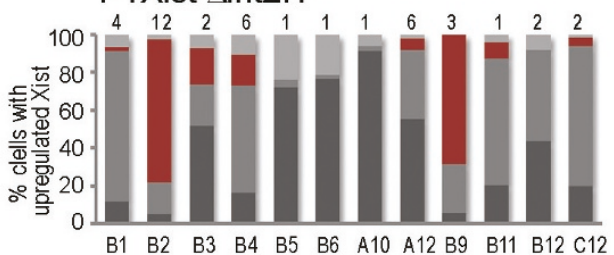

P1Xist $\Delta$ int2.1 $\Delta \mathrm{CpG}$

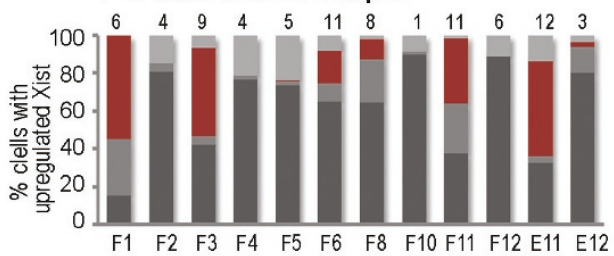

B
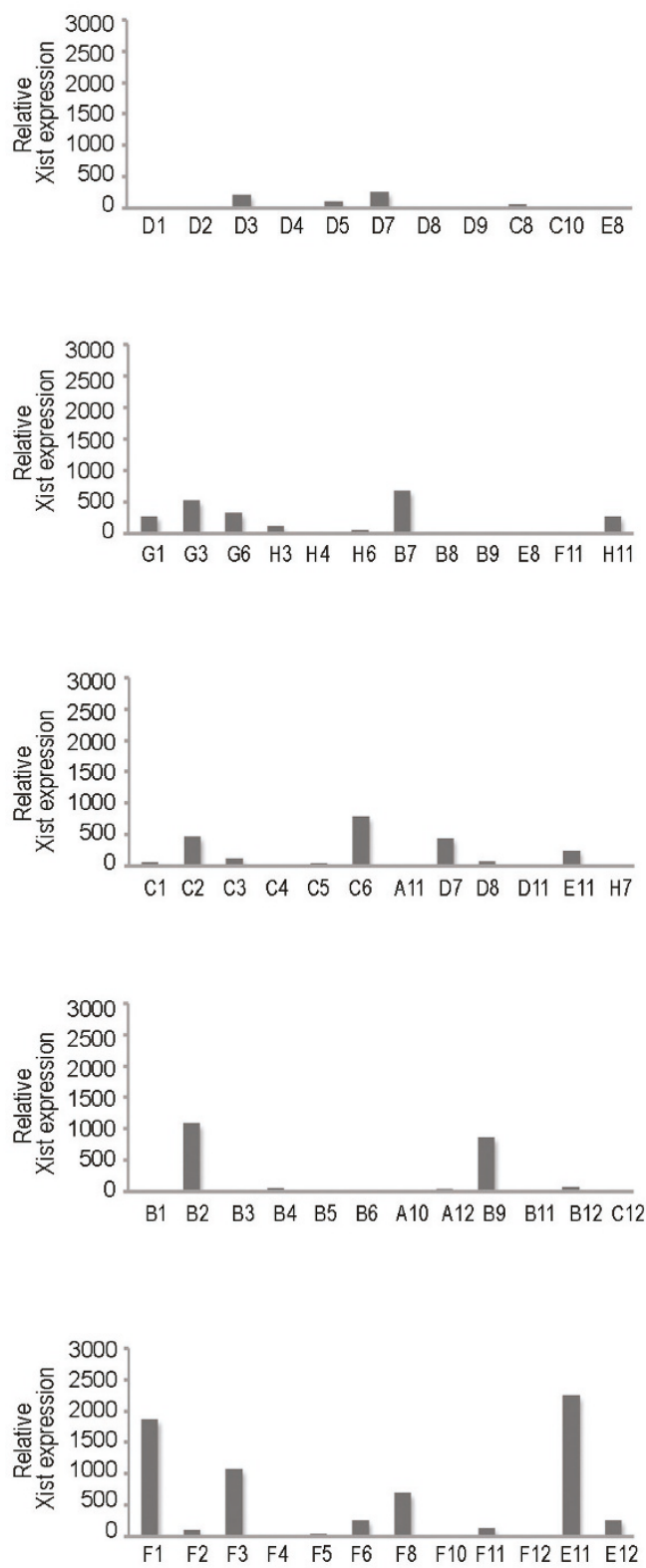

Figure 3 Deletion of Xist intron 1 and the Tsix promoter causes upregulation of transgenic Xist expression in undifferentiated XY ES cell lines. (A) Graphs showing proportional representation of four patterns of Xist expression in XY ES clones carrying P1 transgenes: light grey, no detectable Xist expression; red, upregulated Xist cloud; grey, two punctate Xist signals; dark grey, one punctate Xist signal. Each bar represents an individual clone. (B) qRT-PCR analysis of Xist expression in XY ES clones carrying P1 transgenes. All data is normalised to $\beta$-actin transcript levels and presented relative to the wt XY ES (129/1) Xist RNA level. Each bar represents an individual clone. ES: embryonic stem; qRTPCR: quantitative reverse transcription polymerase chain reaction; wt: wild type.

Xist and Tsix probes (Additional file 2), suggesting that the P1 transgene integrated in multicopy in an open chromatin environment, leading to misexpression of both Xist and Tsix loci. This clone was therefore excluded from further analysis. Together, these results indicate that deletion of the NOS binding region leads to moderate upregulation of Xist expression in undifferentiated ES cells. 
Our bioinformatic analysis revealed several other binding sites for Nanog, Oct4 and Sox2 spread throughout Xist intron 1 . We decided to extend the deletion and remove $2.1 \mathrm{~kb}$ of intron 1 ( $\Delta$ int2.1) to test whether these other sites contribute to the repression of Xist (Figure 2A). RNA FISH analysis of a series of clones yielded results similar to those obtained for $\Delta$ int 0.3 (Figure 2B, C, Figure 3A). Once again, the degree of Xist upregulation varied between clones (0\% to $76 \%)$ and the Xist domains observed were similar to those in $\Delta$ int 0.3 clones. This result indicated that the repressive function of intron 1 maps predominantly to the $0.3 \mathrm{~kb}$ minimal binding region.

We went on to analyse the degree of Xist upregulation by quantitative RT-PCR (qRT-PCR). As expected, clones that showed Xist domains by RNA FISH analysis also showed higher levels of Xist expression (Figure 3B). Further, our RT-PCR analysis of Xist exon-intron structure demonstrated that Xist RNA was spliced correctly (data not shown). On average, Xist was upregulated approximately four times over the level of Xist in P1 wt ES cells for both $\Delta$ int 0.3 and $\Delta$ int2.1 (Figure 2E). Taking into account that only $50 \%$ to $60 \%$ of clones had demonstrated a substantial proportion of cells with an Xist domain (Figure 2D), the degree of Xist upregulation in clones with the domain was considerably higher (Figure 3B). Thus deletion of the binding region for Nanog, Oct 4 and Sox2 located within the Xist intron 1 caused derepression of $X i s t$, albeit to varying degrees between and within different clones.

\section{Simultaneous deletion of Xist intron 1 and the Tsix promoter facilitates derepression of Xist expression}

The non-coding RNA Tsix is transcribed in an antisense orientation through the entire Xist locus and is regarded as a major repressor of Xist in undifferentiated ES cells [26]. However, a deletion of the Tsix promoter or premature termination of the Tsix transcript causes only limited Xist upregulation [20,21]. We hypothesised that Tsix and Xist intron 1 may function redundantly in repressing Xist in undifferentiated ES cells. To test this, a deletion of the Tsix promoter and the major transcriptional start site $(\Delta \mathrm{CpG})[26]$ was introduced by recombineering into the control P1 construct $(\triangle \mathrm{CpG})$ and in the P1 construct carrying the large intron 1 deletion ( $\Delta$ int $2.1 \Delta \mathrm{CpG})$.

Twelve clones carrying each P1 construct were analysed by RNA FISH for the presence of an Xist domain. Several $\triangle \mathrm{CpG}$ clones had $1 \%$ to $10 \%$ of cells with a small Xist cluster, consistent with previous observations using Tsix mutant ES cells [21]. Two clones showed somewhat higher numbers of cells with a small Xist domain (23\% and 36\%), which was probably due to the site of integration or copy number (Figure $3 \mathrm{~A}$ ). Around half of the $\Delta \mathrm{int} 2.1 \Delta \mathrm{CpG}$ clones had an Xist accumulated domain, a result similar to
$\Delta$ int2.1 alone. However, the accumulated domain was generally larger in the clones that showed upregulation and the overall proportion of cells with the domain within those clones was higher (Figure 4A-C). qRT-PCR analysis confirmed the latter observation as average Xist expression was more than two-fold higher in $\Delta$ int $2.1 \Delta \mathrm{CpG}$ compared with $\Delta$ int 2.1 or $\triangle \mathrm{CpG}$ alone (Figure $3 \mathrm{~B}, 4 \mathrm{D}$ ).

While the results of these experiments clearly indicated that Xist intron 1 and Tsix contribute synergistically to the repression of Xist in undifferentiated ES cells, there was considerable variability of Xist derepression between different clones. A relatively high proportion of clones and/or cells carrying P1 with single or double deletions did not exhibit an Xist domain in spite of initial positive genotyping for the presence of a P1 transgene. There are several possible causes for this variability, namely copy number of the transgene, site of integration, orientation of transgenic copies and transgene instability. Using qPCR and Southern blot hybridisation we estimated copy number of Xist transgenes to vary between one and fourteen. There is a general correlation, in that clones with higher transgene copy numbers are more likely to show some degree of Xist upregulation. However, this is not absolute and some clones with just two copies of the transgene show much higher upregulation than clones with higher copy number.

Southern blot analysis revealed that the majority of clones have rearrangements, indicating transgene instability (Additional file 3 ). We reasoned that since the clonal analysis requires prolonged passaging of cells in culture, this could enhance frequency of transgene rearrangements due to selective pressure or/and transgene instability over time. To minimize this effect, we decided to use a different approach and analyse pooled clones after co-lipofection of P1 transgene with a pPGKpuro selective plasmid immediately after they have undergone a selection for transgene integration. This approach has the disadvantage that not every clone will contain a P1 construct, but assuming that all parameters are the same, pools with different P1 constructs will have similar lipofection efficiency and average transgene copy number. We performed the experiment on three different pools for each construct to account for experimental variability. Initially we analysed each pool individually by Southern blot hybridisation analysis to determine the average copy number and assess transgene integrity. As anticipated, pooled clones with minimal passaging time did not show any transgene rearrangements (Figure 5A). Transgene copy number varied between the experiments, but was broadly similar between the different pools within each experiment (Figure 5A).

RNA FISH analysis of the pooled clones confirmed the data from the analysis of individual clones, and pools carrying $\Delta$ int2.1 $\Delta \mathrm{CpG}$ showed the highest proportion of 
A

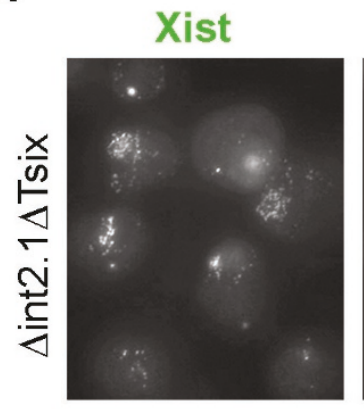

B

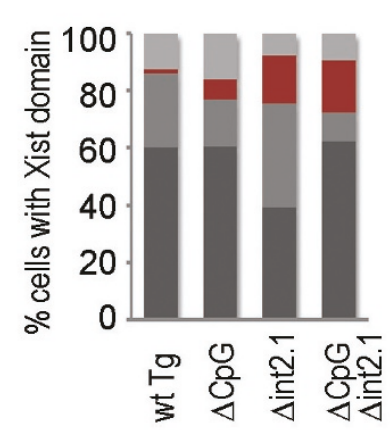

Tsix

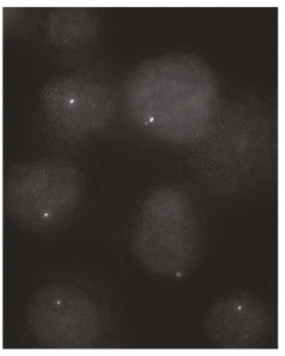

C

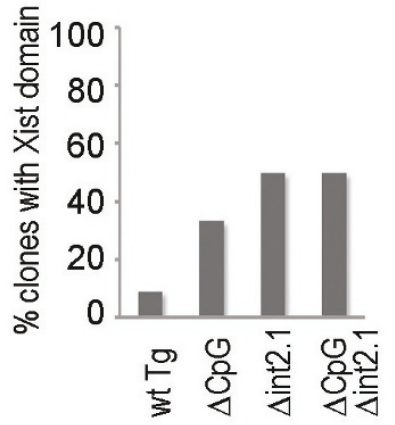

DAPI

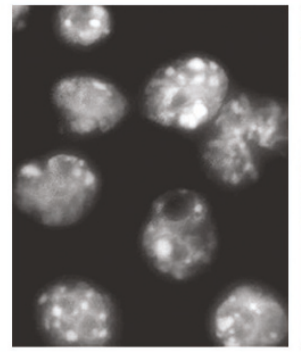

D
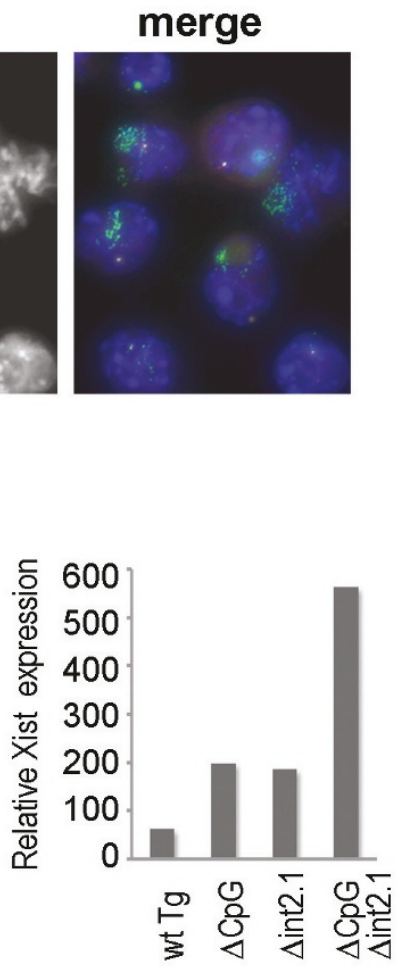

Figure 4 Simultaneous deletion of the Tsix CpG island and Xist intron 1 further increases transgenic Xist activation in undifferentiated XY ES cell lines. (A) RNA FISH analysis of Xist and Tsix expression in undifferentiated XY ES clones carrying P1 construct with deletion of the Tsix promoter $(\triangle \mathrm{C} \mathrm{pG})$ and Xist intron 1 (Aint2.1, clone L8F1). (B) Graph showing proportional representation of four patterns of Xist expression in XY ES clones carrying P1 transgenes. Average data for 12 clones of each genotype are shown. Individual clone data are shown in Figure 3A. (C) A graph showing the percentage of clones with upregulated Xist. (D) qRT-PCR analysis of Xist expression in XY ES clones carrying either wt P1, P1 with deletion of Tsix promoter $(\Delta \mathrm{CpG}), \mathrm{P} 1$ with $2.1 \mathrm{~kb}$ (Aint2.1) deletion in Xist intron 1 or simultaneous deletion of Tsix promoter ( $\triangle \mathrm{CpG}$ ) and Xist intron 1 ( $\Delta$ int2.1). All data is normalised to $\beta$-actin transcript levels and presented relative to the wt XY ES (129/1) Xist RNA level. Average data for 12 clones of each genotype are shown. Individual clone data are shown in Figure 3B. See Figure 2 for detailed annotation. ES: embryonic stem; FISH: fluorescent in situ hybridisation; qRT-PCR: quantitative reverse transcription polymerase chain reaction; wt: wild type.

cells with an Xist domain (not shown). To quantify this we analysed Xist upregulation in clone pools by qRTPCR. Average data were obtained for three primer pairs along the Xist transcript (ex1, ex2-3 and ex4-5) for each of the pools. We observed variability in the degree of $X i s t$ upregulation between the experiments, however pools with $\Delta$ int $2.1 \Delta \mathrm{CpG}$ consistently showed the highest Xist expression level (Figure 5B).

Taken together, our results suggest that the Xist intron 1 region is important for Xist repression in undifferentiated pluripotent cells, as proposed previously [22], but that it functions synergistically with Tsix, the two mechanisms acting redundantly. The latter finding may provide some explanation for the observations of Barakat and colleagues [23], who did not detect Xist upregulation in undifferentiated XX ES cells carrying deletion of the intron 1 NOS on one allele. Our data show that the intron 1 NOS behaves as a classical silencer element in that it can function in a distance and orientation independent manner.

Whilst our results provide clear evidence supporting a role of the intron 1 NOS in Xist repression, the Xist upregulation we observed from mutant transgenes is relatively variable, both between clones and within individual clones, and rarely occurs to the extent seen in XX somatic cells. It is possible that this variability and low expression is a consequence of selection against the cells which upregulate Xist and silence autosomal genes in cis, although arguing against this we did not observe increased lethality in clones with high transgenic Xist expression. A more plausible explanation is that other repressors and/or Xist activators play a role. Sado and colleagues [27] observed significant upregulation of the Xist promoter in ES cells carrying a deletion of a large region including much of Xist exon 1 and some of Xist intron 1. Whilst it is possible that this deletion disrupts 
A

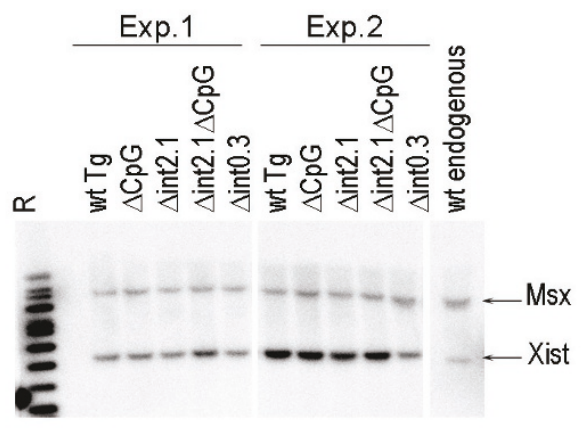

B

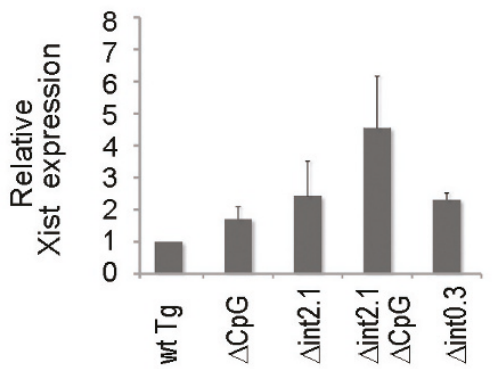

Figure 5 Analysis of Xist expression in lipofected cell pools. (A) Southern blot analysis of DNA extracted from the cell pools 12 days after lipofection of P1 transgenes into undifferentiated XY ES cells. Data for two experiments are shown. (B) qRT-PCR analysis of Xist expression in XY ES cell pools transfected with P1 transgenes. All data is normalised to $\beta$-actin and wt Xist transcript level in XY ES cells (129/1). The average value from three independent experiments (+ SEM) is shown for each transgenic genotype. ES: embryonic stem; Msx: homeobox, msh-like 1 autosomal gene used for internal normalisation; qRT-PCR: quantitative reverse transcription polymerase chain reaction; R: Raoul marker; wt: wild type.

normal function of the intron 1 NOS and/or Tsix, it is also possible that other unidentified functional sequences have been removed. Also relevant is that synergistic function of the intron 1 NOS and Tsix cannot account for Xist repression in PGCs as Tsix appears not to be expressed in this context $[13,14]$, again suggesting that other factors can contribute. Finally, it is not known the degree to which levels of Xist activators, for example Rnf12 [23,28] or the Jpx/Enox ncRNA [29] could contribute to reduced Xist expression in pluripotent cells. A recent study indicates that pluripotency factors repress levels of Rnf12 [30], although set against this, ectopic expression of Rnf12 in ES cells with the intron 1 NOS deletion does not trigger Xist upregulation [23].

\section{Conclusion}

Our results show that Xist repression in undifferentiated ES cells is controlled by synergistic and/or redundant mechanisms. Binding of pluripotency factors to the element in Xist intron 1 contribute to Xist repression, as does transcription of the antisense RNA, Tsix. However, ablation of these two pathways does not lead to complete derepression, indicating that other pathways must also be involved.

\section{Methods}

Cell culture

The 129/1 ES cell line [31] was grown as previously described [32]. ES cells were lipofected with P1 DNA using Lipofectamine 2000 (Invitrogen, UK) according to the manufacturer's instructions. The night before transfection, $1 \times 10^{6}$ cells were seeded in antibiotic-free medium on a well of a six-well plate. The cells were co-lipofected with $2 \mu \mathrm{g}$ of P1 DNA and 50 ng of selective plasmid with the puromycin resistance gene under the PGK promoter with a 1:3 ratio between DNA and Lipofectamine 2000. The cells were trypsinised $24 \mathrm{~h}$ later and replated on a 90 $\mathrm{mm}$ Petri dish seeded with puromycin-resistant mitomycin (Sigma-Aldrich, UK)-inactivated feeder cells. Puromycin selection $(2 \mu \mathrm{g} / \mathrm{mL})$ was applied $48 \mathrm{~h}$ after lipofection. Puromycin-resistant colonies were either picked individually and expanded for analysis 12 days later or all colonies were pooled together and analysed 11 days after transfection.

The XEN16 cell line derived in house was cultured in Royal Park Memorial Institute (RPMI) 1640 medium supplemented with 10\% FCS, 100 units/mL penicillin, $100 \mu \mathrm{g} /$ $\mathrm{mL}$ streptomycin, $2 \mathrm{mM}$ L-glutamine, $1 \mathrm{mM}$ sodium pyruvate and $50 \mu \mathrm{M} \beta$-mercaptoethanol (all reagents from Invitrogen unless otherwise stated). This cell line was used as a negative control for ChIP with Nanog antibody (Cosmo Bio Co., Ltd, Japan) as XEN cells do not express Nanog.

\section{Recombineering}

GalK-mediated recombineering in the P1 15503 (Incyte Genomics, USA) clone was performed essentially as previously described [25]. Arms of homology for each of the recombineering constructs were cloned into the pBluescript plasmid and the GalK gene was inserted in between. These GalK-carrying plasmids were used for the first round of recombineering to replace a region of interest with the GalK selective gene. pBluescipt plasmids with arms of homology only were used for the second round of recombineering to remove GalK. Primers used for PCR to amplify the arms of homology are listed in Additional file 4.

\section{RT-PCR analysis}

RNA was isolated using TRIZOL reagent (Invitrogen) and treated with Turbo DNA-free reagent (Applied Biosystems, UK) according to the manufacturer's instructions. cDNA synthesis was primed from random hexamers (GE Healthcare, Life Sciences, UK) with Superscript III reverse transcriptase (Invitrogen). qRT-PCR was performed with 
SYBR Green PCR Master Mix (BioRad Laboratories, UK) on a Chromo4 Real-time PCR System (BioRad Laboratories). PCR primers and conditions were as described previously [33]. The data was normalised to $\beta$-actin and then to the $129 / 1$ control ES cell line.

\section{RNA FISH analysis}

RNA FISH was performed essentially as described previously [34]. pXist, an $18 \mathrm{~kb}$ DNA fragment spanning the whole Xist transcript, was directly labelled using Spectrum Green-dUTP and nick translation kit (both from Abbott Diagnostics, Abbot UK). A Spectrum Red-dUTP (Abbott Diagnostics)-directly labelled $2.5 \mathrm{~kb}$ PCR fragment from the region immediately downstream from the $\Delta \mathrm{CpG}$ deletion was used as a Tsix probe. Images were acquired on a Zeiss AX10 microscope equipped with AxioCam MRm charge-coupled device camera using AxioVision software (Carl Zeiss International, UK).

\section{Immunofluorescence}

ES cells were trypsinised, rinsed with EC10 medium followed by a PBS wash and cytospun onto Superfrost Plus glass slides (VWR, UK) at $1800 \mathrm{rpm}$ for $3 \mathrm{~min}$ (Cytospin centrifuge; Shandon, Pittsburgh). Immunofluorescence was then performed as described previously [35].

\section{Chromatin immunoprecipitation}

Cells were trypsinised, washed with ice-cold PBS and fixed in $1 \%$ formaldehyde in PBS for $10 \mathrm{~min}$ at room temperature with constant rotation. The crosslinking reaction was quenched by the addition of $1 / 10$ volume of $1.25 \mathrm{M}$ glycine. After washing in ice-cold PBS, the cells were lysed in ChIP lysis buffer (50 mM Tris, pH 8.0; 10 mM EDTA; 1\% SDS), containing protease inhibitors (Complete mini, Roche Diagnostic, UK). The lysates were sonicated using a Bioruptor sonicator (Diagenode, Belgium) to yield fragment sizes between 300 and $500 \mathrm{bp}$ and stored at $-80^{\circ} \mathrm{C}$ until immunoprecipitation was carried out. The lysate containing the chromatin was diluted 1:10 in dilution buffer (1\% Triton X-100, 2 mM EDTA pH8.0, $150 \mathrm{mM} \mathrm{NaCl}$, $20 \mathrm{mM}$ Tris- $\mathrm{HCl} \mathrm{pH} \mathrm{8,} \mathrm{protease} \mathrm{inhibitors).} 75 \mu \mathrm{g}$ chromatin was then incubated with $4 \mu \mathrm{g}$ antibody (anti-Nanog, Cosmo Bio; anti-Oct4 sc-8628X, Santa Cruz; immunoglobulin G, Abcam, UK or Sigma-Aldrich) overnight at $4^{\circ} \mathrm{C}$ and then with protein $\mathrm{G}$ agarose beads pre-blocked with salmon sperm DNA (Millipore (UK) Ltd) for $3 \mathrm{~h}$ at $4^{\circ} \mathrm{C}$. The beads were washed four times in low salt wash buffer (0.1\% SDS, 1\% Triton X-100, 2 mM EDTA, $150 \mathrm{mM}$ $\mathrm{NaCl}, 20 \mathrm{mM}$ Tris- $\mathrm{HCl} \mathrm{pH}$ 8, protease inhibitors) and once in high salt wash buffer $(0.1 \%$ SDS, $1 \%$ Triton X-100, 2 mM EDTA, $500 \mathrm{mM} \mathrm{NaCl}, 20 \mathrm{mM}$ Tris-HCl pH 8, protease inhibitors). Immunoprecipitated DNA was eluted from the beads by incubation in elution buffer (1\% SDS,
$0.1 \mathrm{M}$ sodium bicarbonate) with $150 \mu \mathrm{g}$ proteinase $\mathrm{K}$ and $50 \mu \mathrm{g}$ RNaseA for $2 \mathrm{~h}$ at $37^{\circ} \mathrm{C}$ and overnight at $65^{\circ} \mathrm{C}$. DNA was then isolated by standard phenol:chloroform extraction. qPCR analysis of isolated DNA was performed on Chromo4 Real-time PCR System (BioRad Laboratories) using primers and conditions listed in Additional File 4.

\section{Additional material}

\begin{abstract}
Additional file 1: An inducible P1 Xist transgene triggers repressive histone tail modifications upon induction with doxycycline. (A) Schematic representation of $\mathrm{XIC}$ region cloned into bacteriophage clone P1 15503 (P1). Relative positions of Xist gene (blue rectangle), Tsix promoter and TSS (dark grey box and arrow) and TRE (red box and arrow) are shown. Arrows indicate the direction of transcription. (B) RNA FISH analysis of Xist expression (green) in an undifferentiated XY ES line carrying an inducible P1 Xist transgene before (-dox) and after 1 day (+dox) of treatment with doxycycline. (C) Representative examples of H3K27me3 and H2AK119u1 staining of an undifferentiated XY ES line carrying an inducible P1 Xist transgene after one day of treatment with doxycycline.
\end{abstract}

Additional file 2: Xist upregulation in the wt P1 clone D6 is caused by a different mechanism. Representative examples of cells from P1 wt D6, P1 $\triangle$ int2.1 B2 and P1 $\triangle$ int2.1 $\triangle$ CpG F1 clones are shown. Note the presence of large upregulated Tsix domain co-localising with

upregulated Xist domain in P1 wt D6 and absence of Tsix domain in the P1 deletion mutant clones. Green arrows point to the Xist domain and red arrows indicate the corresponding position the red channel (Tsix probe). Directly labelled full length Xist cDNA (Xist, Spectrum Green, Abbott Diagnostics) and $2.6 \mathrm{~kb}$ Tsix fragment non-overlapping with the $\triangle \mathrm{CpG}$ deletion (Tsix, Spectrum Red, Abbott Diagnostics; $29.8 \mathrm{~kb}$ downstream from the Xist TSS) were used as probes.

Additional file 3: Analysis of Xist expression in P1 transgenic clones Representative examples of Southern blot analysis of genomic DNA extracted from the ES clones lipofected with P1 transgenes. Genotype of P1 clone used for lipofection is indicated above the blots. R, Raoul marker (MP Biomedicals UK); Msx, homeobox, msh-like 1 autosomal gene used for internal normalisation.

Additional file 4: Supplemental table 1. File contains a list of primers and PCR conditions used for ChIP analysis and to amplify arms of homology in P1 recombineering assay.

\section{Abbreviations}

ChIP: chromatin immunoprecipitation; EDTA: ethylenediaminetetraacetic acid: ES: embryonic stem; FCS: foetal calf serum; FISH: fluorescent in situ hybridisation; Galk: galactokinase; ICM: inner cell mass; NOS: Nanog/Oct4/ Sox2; PBS: phosphate buffered saline; PCR: polymerase chain reaction; PGC: primordial germ cell; PGK: phosphoglycerate kinase; qRT-PCR: quantitative reverse transcription $P C R ; R T$ : reverse transcription; TSS: transcriptional start site; wt: wild type; XEN: extraembryonic endoderm; Xist: $X$ inactive specific transcript; Xi: inactive $\mathrm{X}$ chromosome; $\mathrm{Xp}$ : paternal $\mathrm{X}$ chromosome.

\section{Acknowledgements}

We would like to thank members of the laboratory for helpful discussion and critical reading of the manuscript. This work was funded by the Wellcome Trust, UK.

\section{Author details}

${ }^{1}$ Developmental Epigenetics Group, Department of Biochemistry, University of Oxford, South Parks Road, Oxford, OX1 3QU, UK. 'Epigenetics Programme, The Babraham Institute, Babraham Research Campus, Cambridge CB22 3AT, UK. ${ }^{3}$ Molecular Haematology Unit, Weatherall Institute of Molecular Medicine, John Radcliffe Hospital, Oxford University, Oxford, OX3 9DS, UK. 


\section{Authors' contributions}

TBN, CES and NB conceived of and designed the experiments. TBN, CES, JS, TAS and AT performed the experiments. TBN, CES, JS, TAS, AT, MH and NB analysed the data. MH contributed reagents and materials. TBN, CES and NB wrote the paper. All authors read and approved the final manuscript.

\section{Competing interests}

The authors declare that they have no competing interests.

Received: 11 August 2011 Accepted: 7 October 2011

Published: 7 October 2011

\section{References}

1. Lyon MF: Gene action in the X-chromosome of the mouse (Mus musculus L.). Nature 1961, 190:372-373.

2. Avner $\mathrm{P}$, Heard $\mathrm{E}: \mathrm{X}$-chromosome inactivation: counting, choice and initiation. Nat Rev Genet 2001, 2:59-67.

3. Chow J, Heard $\mathrm{E}: \mathrm{X}$ inactivation and the complexities of silencing a sex chromosome. Curr Opin Cell Biol 2009, 21:359-366.

4. Mak W, Nesterova TB, de Napoles M, Appanah R, Yamanaka S, Otte AP, Brockdorff $\mathrm{N}$ : Reactivation of the paternal $\mathrm{X}$ chromosome in early mouse embryos. Science 2004, 303:666-669.

5. Okamoto I, Otte AP, Allis CD, Reinberg D, Heard E: Epigenetic dynamics of imprinted X inactivation during early mouse development. Science 2004, 303:644-649.

6. Panning B, Dausman J, Jaenisch R: $\mathrm{X}$ chromosome inactivation is mediated by Xist RNA stabilization. Cell 1997, 90:907-916.

7. Sheardown SA, Duthie SM, Johnston CM, Newall AE, Formstone EJ, Arkell RM, Nesterova TB, Alghisi GC, Rastan S, Brockdorff N: Stabilization of Xist RNA mediates initiation of $X$ chromosome inactivation. Cell 1997, 91:99-107.

8. Kunath T, Arnaud D, Uy GD, Okamoto I, Chureau C, Yamanaka Y, Heard E, Gardner RL, Avner P, Rossant J: Imprinted X-inactivation in extraembryonic endoderm cell lines from mouse blastocysts. Development 2005, 132:1649-1661

9. Mak W, Baxter J, Silva J, Newall AE, Otte AP, Brockdorff N: Mitotically stable association of polycomb group proteins eed and en $\times 1$ with the inactive X chromosome in trophoblast stem cells. Curr Biol 2002, 12:1016-1020.

10. Marahrens Y, Panning B, Dausman J, Strauss W, Jaenisch R: Xist-deficient mice are defective in dosage compensation but not spermatogenesis. Genes Dev 1997, 11:156-166.

11. Takagi N, Sasaki M: Preferential inactivation of the paternally derived $\mathrm{X}$ chromosome in the extraembryonic membranes of the mouse. Nature 1975, 256:640-642

12. Chuva de Sousa Lopes SM, Hayashi K, Shovlin TC, Mifsud W, Surani MA, McLaren A: X chromosome activity in mouse XX primordial germ cells. PLoS Genet 2008, 4:e30

13. de Napoles M, Nesterova T, Brockdorff N: Early loss of Xist RNA expression and inactive $\mathrm{X}$ chromosome associated chromatin modification in developing primordial germ cells. PLoS One 2007, 2:e860.

14. Sugimoto $\mathrm{M}, \mathrm{Abe} \mathrm{K}: \mathrm{X}$ chromosome reactivation initiates in nascent primordial germ cells in mice. PLoS Genet 2007, 3:e116.

15. Eggan $K$, Akutsu $H$, Hochedlinger $K$, Rideout W, Yanagimachi R, Jaenisch $R$ $\mathrm{X}$-Chromosome inactivation in cloned mouse embryos. Science 2000, 290:1578-1581.

16. Silva J, Barrandon O, Nichols J, Kawaguchi J, Theunissen TW, Smith A: Promotion of reprogramming to ground state pluripotency by signal inhibition. PLOS Biol 2008, 6:e253.

17. Tada M, Takahama Y, Abe K, Nakatsuji N, Tada T: Nuclear reprogramming of somatic cells by in vitro hybridization with ES cells. Curr Biol 2001, 11:1553-1558.

18. Csankovszki G, Nagy A, Jaenisch R: Synergism of Xist RNA, DNA methylation, and histone hypoacetylation in maintaining $X$ chromosome inactivation. J Cell Biol 2001, 153:773-784.

19. Wutz $A$, Jaenisch $R: A$ shift from reversible to irreversible $X$ inactivation is triggered during ES cell differentiation. Mol Cell 2000, 5:695-705.

20. Luikenhuis $S$, Wutz A, Jaenisch R: Antisense transcription through the Xist locus mediates Tsix function in embryonic stem cells. Mol Cell Biol 2001, 21:8512-8520.

21. Sado T, Li E, Sasaki H: Effect of TSIX disruption on XIST expression in male ES cells. Cytogenet Genome Res 2002, 99:115-118.
22. Navarro P, Chambers I, Karwacki-Neisius V, Chureau C, Morey C, Rougeulle C, Avner P: Molecular coupling of Xist regulation and pluripotency. Science 2008, 321:1693-1695.

23. Barakat TS, Gunhanlar N, Pardo CG, Achame EM, Ghazvini M, Boers R, Kenter A, Rentmeester E, Grootegoed JA, Gribnau J: RNF12 activates Xist and is essential for X chromosome inactivation. PLoS Genet 2011, 7: e1002001.

24. Senner CE, Nesterova TB, Norton S, Dewchand H, Godwin J, Mak W, Brockdorff N: Disruption of a conserved region of Xist exon 1 impairs Xist RNA localisation and X-linked gene silencing during random and imprinted X chromosome inactivation. Development 2011, 138:1541-1550.

25. Warming S, Costantino N, Court DL, Jenkins NA, Copeland NG: Simple and highly efficient $B A C$ recombineering using galK selection. Nucleic Acids Res 2005, 33:e36.

26. Lee JT, Lu N: Targeted mutagenesis of Tsix leads to nonrandom $X$ inactivation. Cell 1999, 99:47-57.

27. Sado T, Hoki Y, Sasaki H: Tsix defective in splicing is competent to establish Xist silencing. Development 2006, 133:4925-4931.

28. Jonkers I, Barakat TS, Achame EM, Monkhorst K, Kenter A, Rentmeester E, Grosveld F, Grootegoed JA, Gribnau J: RNF12 is an X-Encoded dosedependent activator of $\mathbf{X}$ chromosome inactivation. Cell 2009, 139:999-1011.

29. Tian $\mathrm{D}$, Sun $\mathrm{S}$, Lee JT: The long noncoding RNA, Jpx, is a molecular switch for X chromosome inactivation. Cell 2010, 143:390-403.

30. Navarro P, Moffat M, Mullin NP, Chambers I: The X-inactivation transactivator Rnf12 is negatively regulated by pluripotency factors in embryonic stem cells. Hum Genet 2011

31. Kay GF, Penny GD, Patel D, Ashworth A, Brockdorff N, Rastan S: Expression of Xist during mouse development suggests a role in the initiation of $X$ chromosome inactivation. Cell 1993, 72:171-182.

32. Penny GD, Kay GF, Sheardown SA, Rastan $\mathrm{S}$, Brockdorff $\mathrm{N}$ : Requirement for Xist in X chromosome inactivation. Nature 1996, 379:131-137.

33. Nesterova TB, Popova BC, Cobb BS, Norton S, Senner CE, Tang YA, Spruce T, Rodriguez TA, Sado T, Merkenschlager M, Brockdorff N: Dicer regulates Xist promoter methylation in ES cells indirectly through transcriptional control of Dnmt3a. Epigenetics Chromatin 2008, 1:2.

34. Cobb BS, Nesterova TB, Thompson E, Hertweck A, O'Connor E, Godwin J, Wilson CB, Brockdorff N, Fisher AG, Smale ST, Merkenschlager M: T cell lineage choice and differentiation in the absence of the RNase III enzyme Dicer. J Exp Med 2005, 201:1367-1373.

35. de Napoles M, Mermoud JE, Wakao R, Tang YA, Endoh M, Appanah R, Nesterova TB, Silva J, Otte AP, Vidal M, Koseki H, Brockdorff N: Polycomb group proteins Ring1 $A / B$ link ubiquitylation of histone $\mathrm{H} 2 \mathrm{~A}$ to heritable gene silencing and $\mathrm{X}$ inactivation. Dev Cell 2004, 7:663-676.

doi:10.1186/1756-8935-4-17

Cite this article as: Nesterova et al:. Pluripotency factor binding and Tsix expression act synergistically to repress Xist in undifferentiated embryonic stem cells. Epigenetics \& Chromatin 2011 4:17.

\section{Submit your next manuscript to BioMed Central and take full advantage of:}

- Convenient online submission

- Thorough peer review

- No space constraints or color figure charges

- Immediate publication on acceptance

- Inclusion in PubMed, CAS, Scopus and Google Scholar

- Research which is freely available for redistribution 